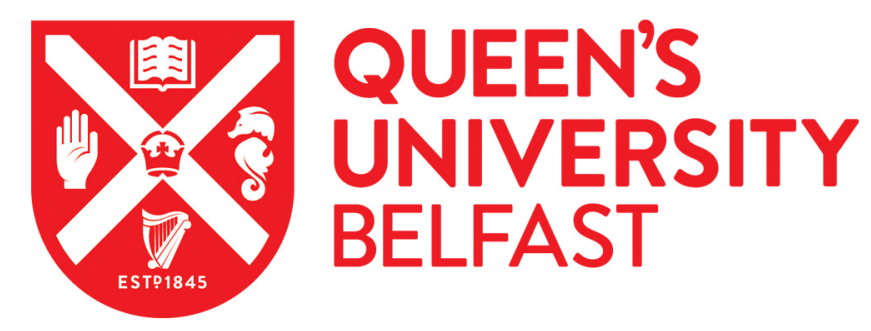

\title{
Patient survival following arteriovenous fistula formation
}

\author{
McGrogan, D. G., Field, M. A., Maxwell, A. P., Marie, Y., \& Inston, N. G. (2015). Patient survival following \\ arteriovenous fistula formation. The journal of vascular access, 16(3), 195-199. \\ https://doi.org/10.5301/jva.5000343
}

\section{Published in:}

The journal of vascular access

\section{Document Version:}

Peer reviewed version

Queen's University Belfast - Research Portal:

Link to publication record in Queen's University Belfast Research Portal

Publisher rights

(c) 2015 Wichtig Publishing

\section{General rights}

Copyright for the publications made accessible via the Queen's University Belfast Research Portal is retained by the author(s) and / or other copyright owners and it is a condition of accessing these publications that users recognise and abide by the legal requirements associated with these rights.

Take down policy

The Research Portal is Queen's institutional repository that provides access to Queen's research output. Every effort has been made to ensure that content in the Research Portal does not infringe any person's rights, or applicable UK laws. If you discover content in the Research Portal that you believe breaches copyright or violates any law, please contact openaccess@qub.ac.uk. 
Patient survival following arteriovenous fistula formation

\section{Authors}

Damian G McGrogan ${ }^{1}$

Melanie A Field ${ }^{1}$

Alexander P Maxwell ${ }^{2}$

Yazin Marie ${ }^{1}$

Nicholas G Inston ${ }^{1}$

\section{Institution}

1. Department of Vascular Access and Renal Transplantation, University Hospitals Birmingham, Queen Elizabeth Hospital, Edgbaston, Birmingham B15 2TH.

2. Regional Nephrology Unit, Belfast Health and Social Care Trust, Belfast City Hospital, 51 Lisburn Road, Belfast, BT9 7AB and School of Medicine, Dentistry and Biomedical Sciences, Health Sciences Building, 97 Lisburn Road, Belfast BT9 7BL.

\section{Corresponding author}

Damian McGrogan, Department of Vascular Access and Renal Transplantation, University Hospitals Birmingham, Queen Elizabeth Hospital, Edgbaston, Birmingham B15 2TH. Tel: 00441216272000

E-mail: damianmcg@gmail.com; damian.mcgrogan@uhb.nhs.uk

Sources of financial support: No competing interest compared $\underline{\text { Type of article for submission Original manuscript }}$ 


\section{ABSTRACT}

Purpose:

Efforts to promote arteriovenous fistulas (AVFs) have been successful in increasing the prevalence of AVF use as the primary vascular access for haemodialysis HD. Sustained preference for AVF use may not be the most appropriate vascular access choice for all patient groups. Arteriovenous grafts (AVGs) offer advantages of earlier use and lower primary failure rates compared to AVFs so may be preferable for patients where short term vascular access is needed. This study was designed to assess comparative mortality in different age groups following AVF formation. Methods:

A prospective cohort of patients having AVF creation was recruited. Patients were subdivided into three age groups; Group A: < 50 years; Group B: 50-74 years and Group C: 75 years. Survival curves and Cox regression analysis was performed on each of these groups.

Results:

One hundred and thirty-four patients $(n=134)$ were recruited into the study. The prevalence of diabetes increased significantly with age. As expected, mortality was higher in older age groups (log rank (mantel cox) 19.227; $p=0.0001)$. Mortality rates at one year were $0 \%$ in group A, $12.5 \%$ in group B and $29.1 \%$ in group C. Medium term mortality at four years was $7.9 \%$ in group A, $39.1 \%$ in group B and $54.8 \% \%$ in group C.

Conclusions:

We found a significantly higher mortality rate in patients $\geq 75$ years in comparison to those $<75$ years. The choice of vascular access modality should be tailored to the individual with particular reference to the patient's expected survival. 
Keywords

arteriovenous fistula; elderly; haemodialysis; mortality 


\section{INTRODUCTION}

The prevalent use of arteriovenous fistulas (AVFs) has increased reflecting initiatives such as Fistula First (http://www.fistulafirst.org/) and promotion of AVFs as the vascular access of choice in national guidelines. $(1,2,3,4)$ The improvement in AVF prevalence is a welcome trend however older patients could be disadvantaged by repeated unsuccessful attempts at surgical AVF creation and resulting overdependence on central venous catheters (CVCs).(5) The age structure of the end-stage renal disease (ESRD) population has changed considerably over the past 20 years with an increasing proportion of older patients ( $>75$ years) receiving dialysis. $(6,7,8)$ Furthermore the progression of chronic kidney disease is typically slower and less predictable in older patients. This can mean in practice that is difficult to ensure timely provision of vascular access for older patients. The significant increase in the number of elderly dialysis patients and the unique challenges they represent for vascular access provision are poorly reflected in guidelines regarding vascular access formation. $(1,2,3,4)$ This is also emphasised in a recent review by Fassett and colleagues(9) of palliative care in ESRD suggesting there is a paucity of robust evidence to predict the outcomes in elderly patients who commence dialysis and therefore decisions regarding their best management remain difficult.

Worldwide, the number of elderly patients with ESRD commencing haemodialysis is rising. In the USA, since 2000 , the adjusted incident rate for dialysis in patients aged $\geq 75$ years has increased by $12.2 \%$.(6) In Canada, the number of incident patients with ESRD aged $\geq 75$ years doubled between 1996 and 2005 whilst the number of incident patients with ESRD aged 20-64 years has decreased in the corresponding 
years.(7) In the UK, from 2005 to 2008 , the number of patients on dialysis aged $\geq 65$ years increased by $29 \%$ compared with an increase of only $16 \%$ in those aged $18-$ 65 years. (8)

Important factors associated with AVF failure in those patients $>67$ years of age include increasing age, female gender, black race, diabetes, cardiac failure and shorter pre-ESRD nephrology care.(10)

Optimal timing of referral for AVF formation is a complex issue in the management of patients with ESRD. Advanced age has been shown to be a risk factor for late referral to nephrologist, increased use of CVCs and increased likelihood of hospital admission, septicaemia and higher mortality. $(11,12)$ It would therefore be important to stratify these patients into groups and decide dialysis needs according to individual profiles and patient preferences rather than a Fistula First "one size fits all" policy.

We sought to prospectively assess the age-related mortality of patients following surgical creation of an AVF and identify the factors contributing to higher mortality rates.

\section{SUBJECTS AND METHODS}

A prospective cohort study was designed and recruited consecutive patients undergoing single incision (radiocephalic, brachiocephalic and first stage brachiobasilic) AVF formation between $8^{\text {th }}$ April 2009 and $30^{\text {th }}$ September 2009. Patients are referred to the vascular access unit following weekly multi-disciplinary team discussions identifying patients who are showing rapid progression of renal 
disease with a glomerular filtration rate of $<15 \mathrm{~mL} / \mathrm{min} / 1.73 \mathrm{~m}^{2}$ or $<20$

$\mathrm{mL} / \mathrm{min} / 1.73 \mathrm{~m} 2$ for patients with diabetes. All surgery was performed in a single centre (Queen Elizabeth Hospital, Birmingham, UK) and all operations were carried out by or under the direct supervision of four consultant surgeons. Information was collated in a vascular access database and included patient age, past medical history, pre-operative haemoglobin concentration, international normalised ratio, systolic and diastolic blood pressures, anticoagulant medications, grade of operating surgeon, type of AVF formed, pre-operative vessel measurements made with Doppler ultrasound assessment and dialysis status. Vessels considered suitable for AVF formation were based on intraluminal size criteria $(2 \mathrm{~mm}$ for artery and $2.5 \mathrm{~mm}$ for vein) and vessel patency. This patient cohort was followed up until $10^{\text {th }}$ August 2013 with outcomes documented focusing on date of death. No system is currently in place within our unit for surveillance of AVF which are found to have achieved radiological adequacy at six weeks but not yet used for dialysis. The study was approved by local audit review board (CARMS-11315) where specific patient consent was not deemed necessary as it was non-interventional and observational. Data was collected and analysed from the electronic patient database using clinical data collected as standard and not study specific. This database is also updated from primary care to ensure all deaths of patients are recorded. Patients were subdivided into age groups accordingly; Group A: < 50 years; Group B: 50-74 years and Group C: $\geq 75$ years of age. Survival analysis was then performed using SPSS 20 for each of these age groups. Cox regression analysis was used to identify clinical factors which impacted upon survival. 


\section{RESULTS}

A total of 147 patients were included in the study. Nine patients were excluded after they underwent a second stage brachiobasilic operation. Two patients were excluded since their operations were for complications of a previously formed fistula (ligation of their AVF; one for aneurysmal development and one for vascular steal). Two further patients were excluded since they had an AVG inserted. This left 134 patients available for survival analysis. Seven patients had their operations performed under general anaesthetic and 127 patients underwent their procedure under local anaesthetic.

Cause of end-stage renal disease (ESRD)

Of the 134 patients included, $32(23.9 \%)$ had diabetes documented as a cause of ESRD. Twenty-three (17.2\%) had an unknown cause, $17(12.7 \%)$ had glomerulonephritis, $11(8.2 \%)$ had hypertension, 6 (4.5\%) had small kidneys, 8 (5.9\%) had polycystic kidney disease, 5 (3.7\%) had reflux nephropathy and $7(5.2 \%)$ had renovascular disease documented as the cause of ESRD. The remaining 25 (18.7\%) had documented diagnoses of amyloidosis, myeloma, obstructive nephropathy, abdominal aortic aneurysm repair, bilateral nephrectomies for renal cell carcinoma, calcineurin inhibitor toxicity, juvenile nephronophthisis, nephrolithiasis, microscopic polyangiitis, post cystectomy for transitional cell carcinoma, renal dysplasia, renal tuberculosis and scleroderma.

Ethnicity 
Eighty-nine (66.4\%) patients were white, 29 (21.6\%) were Indo-Asian, 12 (9.0\%) were black, two (1.5\%) were of mixed ethnicity and two (1.5\%) patients were Chinese.

Past medical history and medications

Prevalence of hypertension and diabetes for the entire cohort was 68.7\% (92 patients) and $35.1 \%$ (47 patients) respectively. Eleven patients $(8.2 \%)$ had previously undergone a renal transplant and six $(4.5 \%)$ had a documented history of peripheral vascular disease. Thirty-nine patients (29.1\%) were on aspirin, seven $(5.2 \%)$ were on clopidogrel and $16(11.9 \%)$ were on warfarin.

Types of arteriovenous fistula formed Sixty two patients (46.3\%) had radiocephalic AVFs, 54 (40.3\%) had brachiocephalic AVFs and 18 (13.4\%) had first stage brachiobasilic AVFs formed.

\section{Dialysis status}

Sixty-one patients (45.5\%) were pre-dialysis, 73 were $(54.5 \%)$ had already commenced dialysis.

Function

Early patency defined as a patent AVF at six week postoperative review was established in $113(84.3 \%)$ patients and 77 (53.8\%) subsequently used for dialysis. No attempt was made to monitor or salvage AVF which failed prior to the six week post-operative review.

\section{Sub-group analysis}


Table I shows the demographics of patients according to age groups. Thirty-eight (28.4\%) patients in group A; $65(48.5 \%)$ in group B; and $31(23.1 \%)$ in group C.

Survival analysis

As expected, mortality was significantly higher with increasing age (log rank (mantel cox) 19.227; $P=0.0001)$. Figure 1 shows mortality rates for each age group. Mortality rates over 4 years were $7.9 \%$ in group A, 38.5\% in group B and $54.8 \%$ in group $\mathrm{C}$. The cumulative survival for each group from year 1 to year 4 is shown in Table II. Mortality rates were not significantly different if patients had commenced dialysis by the time of AVF creation or not. Cox regression analysis for the different variables confirmed that age and diabetes are associated with increased risk of death. In comparison to group A, group B (HR 5.1, Cl 1.5-17.2; $P=0.009)$ and group

C (HR 8.7, Cl 2.5-30.5; $\mathrm{P}=0.001)$ had an increased risk of death. The increased mortality risk with diabetes was not statistically significant (HR 1.5, Cl 0.8-2.7; $P=0.197)$. Gender, ethnicity, hypertension were not associated with an increased risk of death. Peripheral vascular disease was associated with an increased risk of death (HR 2.9, $\mathrm{Cl} 1.0-8.1 ; \mathrm{P}=0.043)$ however less than $5 \%$ of patients had documented history of peripheral vascular disease.

\section{DISCUSSION}

This prospective study demonstrates that older patients referred for AVF surgery have poorer survival compared to younger patients during a four year follow up period. Although this finding is to be expected, reflecting the impact of advancing age 
with associated multiple co-morbidities upon patient survival, it is relevant when deciding on the optimal vascular access procedure for older patients.

The UK Renal Registry $16^{\text {th }}$ Annual Report (13) states that the most common primary renal diagnosis for ESRD in the 2012 incident cohort was diabetes (25.6\%), followed by other (17.7\%), unknown aetiology (15.9\%), glomerulonephritis (14\%), hypertension (7.4\%) and polycystic kidney disease (6.7\%). UK Renal Registry data also shows $70.8 \%$ of incident renal replacement therapy patients to be white, $22.7 \%$ to be South Asian, $5.1 \%$ to be black and $1.4 \%$ other. The causes of incident ESRD and background ethnicity are similar in our cohort. For instance, the prevalence of diabetes $(35.1 \%)$ and peripheral vascular disease $(4.5 \%)$ in our cohort is very similar to UK Renal Registry data showing an overall prevalence of diabetes at $34.8 \%$, and claudication at $6 \%$. Our data is therefore largely representative of the UK population reported in nationally published annual data.(13)

In this cohort a higher number of radiocephalic AVFs (46.3\%) were formed than brachiocephalic AVFs (40.3\%) and first stage brachiobasilic AVFs (7.5\%). This range of AVFs formed is reflective of a larger retrospective cohort published by Weale and colleagues (14) where more radiocephalic (53.9\%) AVFs were formed than brachiocephalic AVFs (46.1\%).

\section{Sub-group analysis}

Diabetes was statistically more prevalent in the over 50 years of age groups. Hypertension was found to be prevalent throughout all age groups and antiplatelet and antithrombotic agent use increased with increasing age undoubtedly reflecting the higher incidence of cardiovascular co-morbidities seen in the aging population. Ethnic background was similar in all age groups. Age did not impact on the type of 
AVF created however in our centre we use Doppler ultrasound measurements to assess blood vessel suitability for AVF formation and therefore do not discriminate by age alone.

Oliva and colleagues (15) report a four year survival of haemodialysis patients over 75 years of age as $39.6 \%$. They compared mortality rates between less than 60 years, 60-75 years and 75 years and over. They found a significantly higher mortality in elderly (>75 years) patients with a cumulative survival of $83.1 \%, 68.3 \%, 53.5 \%$ and $39.6 \%$ after years $1,2,3$, and 4 . We found our cumulative survival rates in patients over 75 years to be $71.0 \%, 58.1 \%, 51.6 \%$ and $41.9 \%$ after years $1,2,3$ and 4 respectively. Interestingly, Oliva and colleagues admit to some biasing of the data since they excluded the 71 patients who died within 90 days of commencing haemodialysis. Our data shows that a substantial number of deaths occur early in patients being referred for vascular access procedures. Approximately $42 \%$ of those over 75 years of age died within 2 years of being referred for a fistula. UK life expectancy data published in 2002 states that at 70 years of age males can expect to live for a further 14.7 years and females 17 years. Similarly for persons of 80 years of age life expectancy is 7.7 years for males and 9.1 years for females. (16) The median survival of our cohort over 75 years is approximately 3 years confirming a shorter life expectancy in the presence of ESRD for those patients referred for fistula formation.

The high primary failure rate for AVFs is a very important issue in the elderly population. The length of time between referral for access formation and surgical procedure has been reported by Rayner and colleagues(17) to be longer than four weeks in $60 \%$ of patients referred, a conclusion that has been subsequently 
supported by Ethier at al. (18) The major advantage of CVCs is that they can be used immediately for dialysis. This advantage has been extended more recently to AVGs specifically designed for use in vascular access surgery as some may be ready for use within 24 hours of insertion. The combined advantage of early cannulation of an AVG and reduced incidence of bloodstream infections (compared to CVCs) means that an AVG may offer the best compromise for vascular access in older patients with limited expected survival.

A critical point emphasized in the paper by Allon and Lok (19) is the inclusion of primary failures in the analysis of AVF compared to AVG. Once primary failure is included overall outcomes are equivalent or better for AVGs compared to AVFs up to 18 months following the initial vascular access surgery. AVGs have been shown to have significantly less primary failures, require fewer interventions to achieve patency and are associated with shorter duration of CVC dependence and CVCrelated infections. AVGs are however associated with poorer cumulative survival compared with AVFs and require more interventions to maintain patency. (20) These conclusions are supported by Oliver at al. (21) who observed a longer period of CVC-dependence and superior patency of AVFs overall but comparable survival when primary failures are included. Indeed, a recent report from the USA has shown the Fistula First Breakthrough Initiative implementation to have increased the use of CVCs with any increased emphasis on in the placement of AVFs coming at the expense of AVGs rather than CVCs. (22) This has been argued to be a reflection of the increased use of CVCs as a temporary bridging measure to allow maturation of AVFs. (23) 
The factors shown by Oliva and colleagues to be associated with an increased mortality were low BMI, CVC as initial vascular access, arterial hypertension, congestive heart failure, late referral to nephrologist, serum albumin level below 3.5 $\mathrm{g} / \mathrm{dL}, \mathrm{Kt} / \mathrm{V}<1.2$ and time of dialysis session less than 180 minutes. The multivariate model found that congestive heart failure, $\mathrm{Kt} / \mathrm{V}<1.2$ and serum albumin level $<3.5$ $\mathrm{g} / \mathrm{dL}$ remained as independent predictors of mortality in those dialysis patients greater than 75 years of age. (15) We found in our cohort that age and peripheral vascular disease to be the only factors associated with significantly increased risk of death.

\section{Limitations}

This is a relatively small cohort of patients however we have shown the demographics to be representative of nationally published reports. A larger national cohort would further support the conclusions drawn here and allow for identification of patient related factors which correlate with a less than two year survival.

\section{Conclusion}

Our results show that elderly patients (>75 years) are much more likely to die within a 2 year period than those less than 75 years of age. In an older population a more tailored approach to vascular access creation is necessary. This study supports an AVG as a suitable first access by demonstrating that survival after AVF formation, whether successful or not is limited and rapid access from an AVG, with avoidance of CVC, is a pragmatic alternative approach to providing vascular access for elderly haemodialysis patients.

\section{Conflict of interest}


None to declare. 


\section{REFERENCES}

1. Vascular Access Work Group. Clinical practice guidelines for vascular access. Am J Kidney Dis 2006; 48(suppl 1): S248-73.

2. Ortega T, Ortega F, Diaz-Corte C, Rebollo P, Ma Baltar J, Alvarez-Grande J. The timely construction of arteriovenous fistulae: a key to reducing morbidity and mortality and to improving cost management. Nephrol Dial Transplant $2005 ; 20: 598-603$.

3. Fluck R, Kumwenda M. Clinical practice guidelines. Vascular access for haemodialysis. UK Renal Association. $5^{\text {th }}$ edition 2011. http://www.renal.org/docs/default-source/guidelinesresources/Vascular_Access_for_Haemodialysis_-_FINAL_VERSION__05_January_2011.pdf?sfvrsn=0

4. Sidawy A, Spergel L, Basarab A et al. The Society for Vascular Surgery: Clinical practice guidelines for the surgical placement and maintenance of arteriovenous hemodialysis access. J Vasc Surg. 2008; 48(Suppl 5):S2-S25.

5. Lee T, Barker J, Allon M. Tunneled catheters in hemodialysis patients: reasons and subsequent outcomes. Am J Kidney Dis 2005; 46: 501-508. 
6. Collins AJ, Foley RN, Herzog C et al. US Renal Data System 2012 Annual Data Report. Am J Kidney Dis. 2013; 61: (Suppl. 1) A7.

7. Prakash S, O'Hare AM. Interaction of aging and chronic kidney disease. Semin Nephrol. 2009; 29: 497-503.

8. Brown EA, Johansson L. Epidemiology and management of end-stage renal disease in the elderly. Nat Rev Nephrol.2001; 7: 591-598.

9. Fassett RG, Robertson IK, Mace R, Youl L, Challenor S, Bull R. Palliative care in end-stage kidney disease. Nephrology (Carlton). 2011; 16(1):4-12.

10. Hod T, Desilva RN, Patibandla BK, Vin Y, Brown RS, Goldfarb-Rumyantzev AS. Factors predicting failure of AV "fistula first" policy in the elderly. Hemodial Int. 2014; 18(2):507-15.

11. Dalrymple LS, Johansen KL, Chertow GM et al. Infection-related hospitalizations in older patients with end-stage renal disease. Am J Kidney Dis 2010; $56: 522-530$.

12. Foote C, Ninomiya T, Gallagher M et al. Survival of elderly dialysis patients is predicted by both patient and practice characteristics. Nephrol Dial Transplant $2012 ; 27: 3581-3587$.

13. Caskey F, Davenport A, Dawnay A et al. 16th Annual Report of the Renal Association. UK Renal Registry. Nephron Clinical Practice 2013; Volume 125 Issue 1-4. 
14. Weale AR, Bevis P, Neary WD et al. Radiocephalic and brachiocephalic arteriovenous fistula outcomes in the elderly. J Vasc Surg. 2008; 47(1):14450.

15. Oliva JS, Roa LM, Lara A et al. Survival and factors predicting mortality in hemodialysis patients over 75 years old. J Nephrol. 2013; 26(1):129-35.

16. Decennial Life Tables - No.16 (2000-2002). Released date 25/06/09. http://www.ons.gov.uk/ons/rel/lifetables/decennial-life-tables/no-16--20002002-/index.html. Last access 31/08/2014.

17. Rayner HC, Pisoni RL, Gillespie BW et al. Creation, cannulation and survival of arteriovenous fistulae: data from the Dialysis Outcomes and Practice Patterns Study. Kidney Int. 2003; 63(1):323-30.

18. Ethier J, Mendelssohn DC, Elder SJ et al. Vascular access use and outcomes: an international perspective from the Dialysis Outcomes and Practice Patterns Study. Nephrol Dial Transplant. 2008; 23(10):3219-26.

19. Allon M, Lok CE. Dialysis fistula or graft: the role for randomized clinical trials. Clin J Am Soc Nephrol. 2010; 5(12):2348-54.

20. Lee T, Barker J, Allon M. Comparison of survival of upper arm arteriovenous fistulas and grafts after failed forearm fistula. J Am Soc Nephrol. 2007; 18(6):1936-41. 
21. Oliver MJ, McCann RL, Indridason OS, Butterfly DW, Schwab SJ.

Comparison of transposed brachiobasilic fistulas to upper arm grafts and brachiocephalic fistulas. Kidney Int 2001 60(4): 1532-1539.

22. Vassalotti JA, Jennings WC, Beathard GA et al. Fistula first breakthrough initiative: targeting catheter last in fistula first. Semin Dial. 2012; 25(3):30310.

23. Spergel LM. Has the Fistula First Breakthrough Initiative caused an increase in catheter prevalence? Semin Dial. 2008;21(6):550-2. 


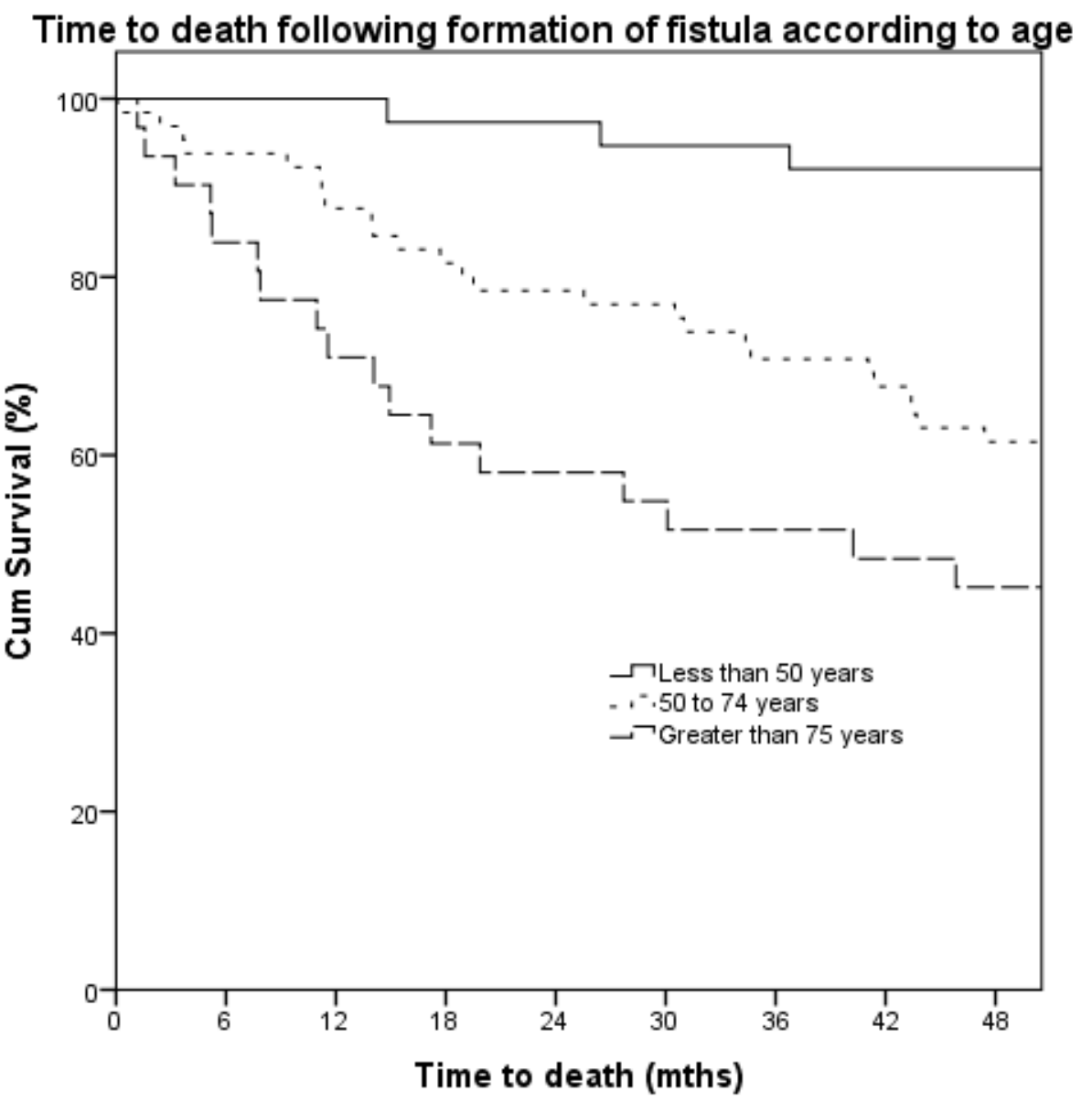

Figure 1: Time to death following formation of fistula according to age. 
Table I: Demographics of patients according to age groups.

\begin{tabular}{|c|c|c|c|c|}
\hline & $\begin{array}{c}\text { Group A } \\
\text { (<50 years) }\end{array}$ & $\begin{array}{c}\text { Group B } \\
\text { (50-74 years) }\end{array}$ & $\begin{array}{c}\text { Group C } \\
\text { (>75 years) }\end{array}$ & $\begin{array}{c}\text { P value } \\
\text { Student's t-test }\end{array}$ \\
\hline Number of patients (\%) & $38(28.4)$ & $65(48.5 \%)$ & $31(23.1 \%)$ & - \\
\hline Sex, male \% & 60.5 & 66.2 & 74.9 & 0.488 \\
\hline $\begin{array}{c}\text { Ethnicity }^{a} \\
\text { W/A/B/M/C }\end{array}$ & $23 / 10 / 4 / 1 / 0$ & $43 / 13 / 6 / 1 / 2$ & $23 / 6 / 2 / 0 / 0$ & 0.832 \\
\hline Diabetes \% & 13.2 & 42.2 & 48.4 & 0.003 \\
\hline Hypertension \% & 78.9 & 65.6 & 64.5 & 0.302 \\
\hline Previous transplant \% & 18.4 & 6.2 & 0 & 0.15 \\
\hline $\begin{array}{c}\text { Peripheral vascular } \\
\text { disease } \%\end{array}$ & 2.6 & 6.7 & 3.2 & 0.644 \\
\hline Warfarin \% & 7.9 & 15.6 & 10 & 0.472 \\
\hline Aspirin \% & 13.2 & 32.8 & 43.3 & 0.019 \\
\hline Clopidogrel \% & 2.6 & 1.6 & 16.7 & 0.007 \\
\hline $\begin{array}{c}\text { Type of fistula formed } \\
\text { RCF/BCF/BBF }\end{array}$ & $18 / 14 / 6$ & $29 / 26 / 10$ & $15 / 14 / 2$ & 0.765 \\
\hline $\begin{array}{c}\text { Pre-dialysis }^{c} \\
\text { ?/Pre/Post }\end{array}$ & $3 / 13 / 22$ & $5 / 25 / 35$ & $2 / 16 / 13$ & 0.673 \\
\hline
\end{tabular}


${ }^{a} \mathbf{W}=$ White; $\mathbf{A}=$ Asian; $B=B l a c k ; \quad M=M i x e d ; C=C h i n e s e$.

${ }^{b} \mathrm{RCF}=$ Radiocephalic fistula; $\mathrm{BCF}=\mathrm{Brachiocephalic}$ fistula; $\mathrm{BBF}=$ First stage brachoibasilic fistula.

${ }^{c} ?=$ unknown dialysis status; Pre=pre-dialysis; Post=commenced dialysis. 
Table II: Cumulative survival (\%) at the end of the year

\begin{tabular}{|ccccc|}
\hline Years & $\mathbf{1}$ & $\mathbf{2}$ & $\mathbf{3}$ & $\mathbf{4}$ \\
\hline Group A (<50 yr) & 100 & 97.4 & 94.7 & 92.1 \\
Group B (50-74 yr) & 87.5 & 78.1 & 70.3 & 60.9 \\
Group C (>75yr) & 70.9 & 58.1 & 51.6 & 45.2 \\
\hline
\end{tabular}

